\title{
MILDER PHENOTYPE OF RELATIVES OF INDEX PATIENTS CAN MISDIAGNOSE FAMILIAL HYPERCHOLESTEROLEMIA
}

A.M. Medeiros ${ }^{1,2}$, A.C. Alves ${ }^{1,2}$, M. Bourbon ${ }^{1,2}$

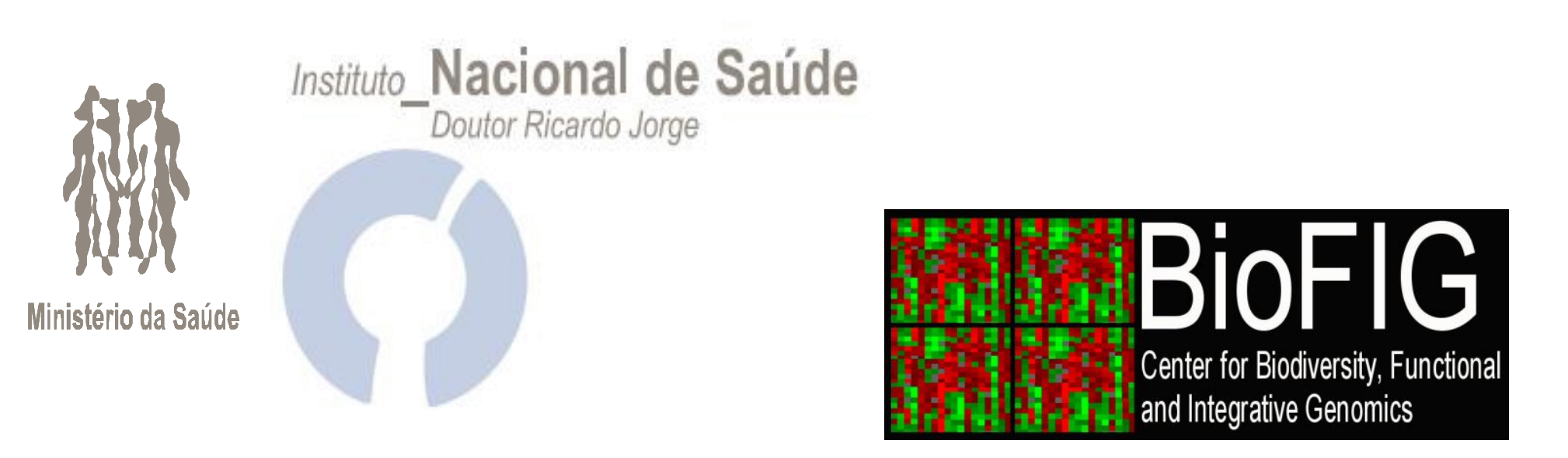

on behalf of the investigators of the Portuguese FH Study

\section{Background.}

Familial Hypercholesterolemia (FH) is a genetic disorder characterized by high levels of LDLc in plasma, accelerated atherosclerosis and increased risk of premature coronary heart disease (pCHD). FH results from mutations in three genes involved in lipid metabolism: LDLR, APOB, PCSK9. It is known that FH patients' phenotype is heterogeneous varying with different conditions, as gene, type of mutation and environment. The present study pretends to characterize the biochemical profile of FH patients genetically identified in Portugal.

\section{- Methods ·}

The genetic diagnosis of FH is based on the analyses of three genes: LDLR, APOB and PCSK9. The Portuguese FH Study identified 420 patients: 182 index ( 60 children, 122 adults) and 238 relatives (56 children, 182 adults) with a genetic defect. Biochemical parameters (total cholesterol (TC), LDLc, HDLc, triglycerides, ApoB, ApoAI), were determined by an colorimetric automated method. The data were analyzed with SPSS software using ANOVA tests.

\section{- Results ·}

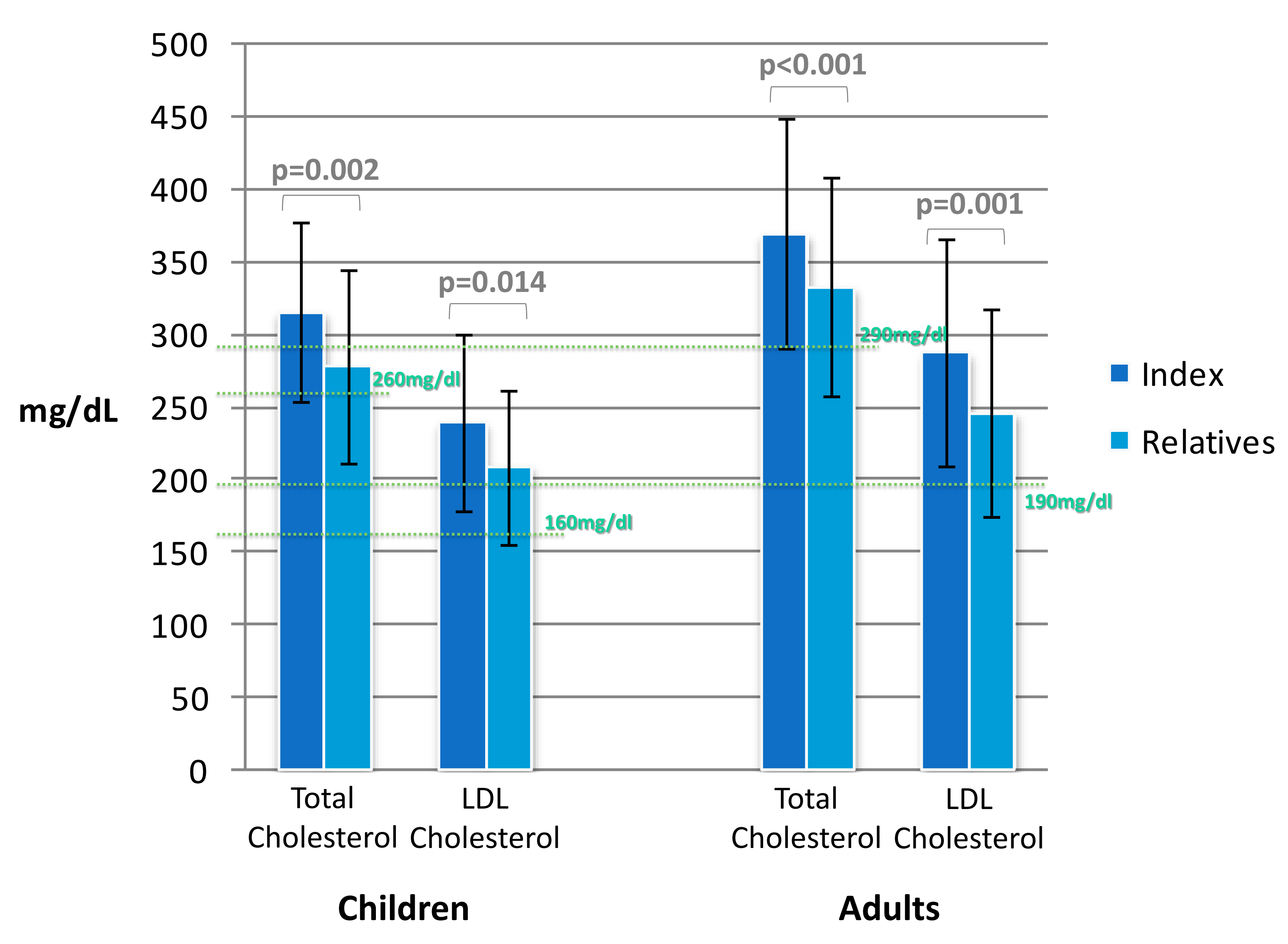

Figure 1. Comparison of biochemical parameters (Total cholesterol and LDL cholesterol) in Portuguese FH index patients vs. relatives identified in cascade screening (CT and LDLc criteria values for FH used are in blue).

- TC and LDLC levels are statistically higher in index patients than in relatives identified in cascade screening (Figure 1 ).

Children: $T C=315.96 \mathrm{mg} / \mathrm{dl}$ and $\mathrm{LDLC}=239.61$ for index vs $\mathrm{TC}=277.52 \mathrm{mg} / \mathrm{dl}$ and $L D L C=209.05 \mathrm{mg} / \mathrm{dl}$ for relatives $(p=0.002, p=0.014)$.

Adults: TC $=369.56 \mathrm{mg} / \mathrm{dl}$ and $\mathrm{LDLC}=287.72 \mathrm{mg} / \mathrm{dl}$ for index vs TC=332.93mg/dl and LDLc=246.26mg/dl for relatives ( $p<0.001, p=0.001)$.

-Although CT and LDLc mean values are above FH criteria $16 \%$ of relatives have both TC and LDLc bellow these values (Figure 1).
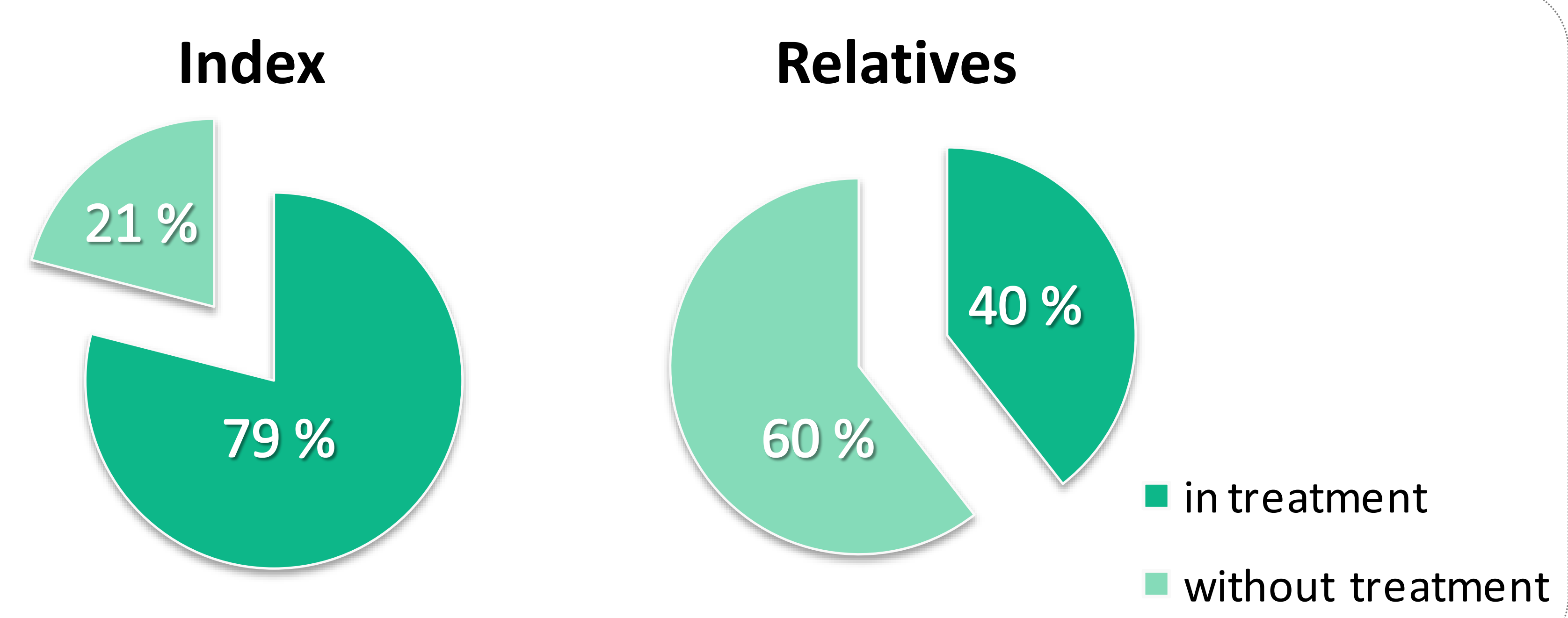

Figure 2. Percentage of adult $\mathrm{FH}$ patients receiving treatment (Index patients vs. relatives identified in cascade screening).

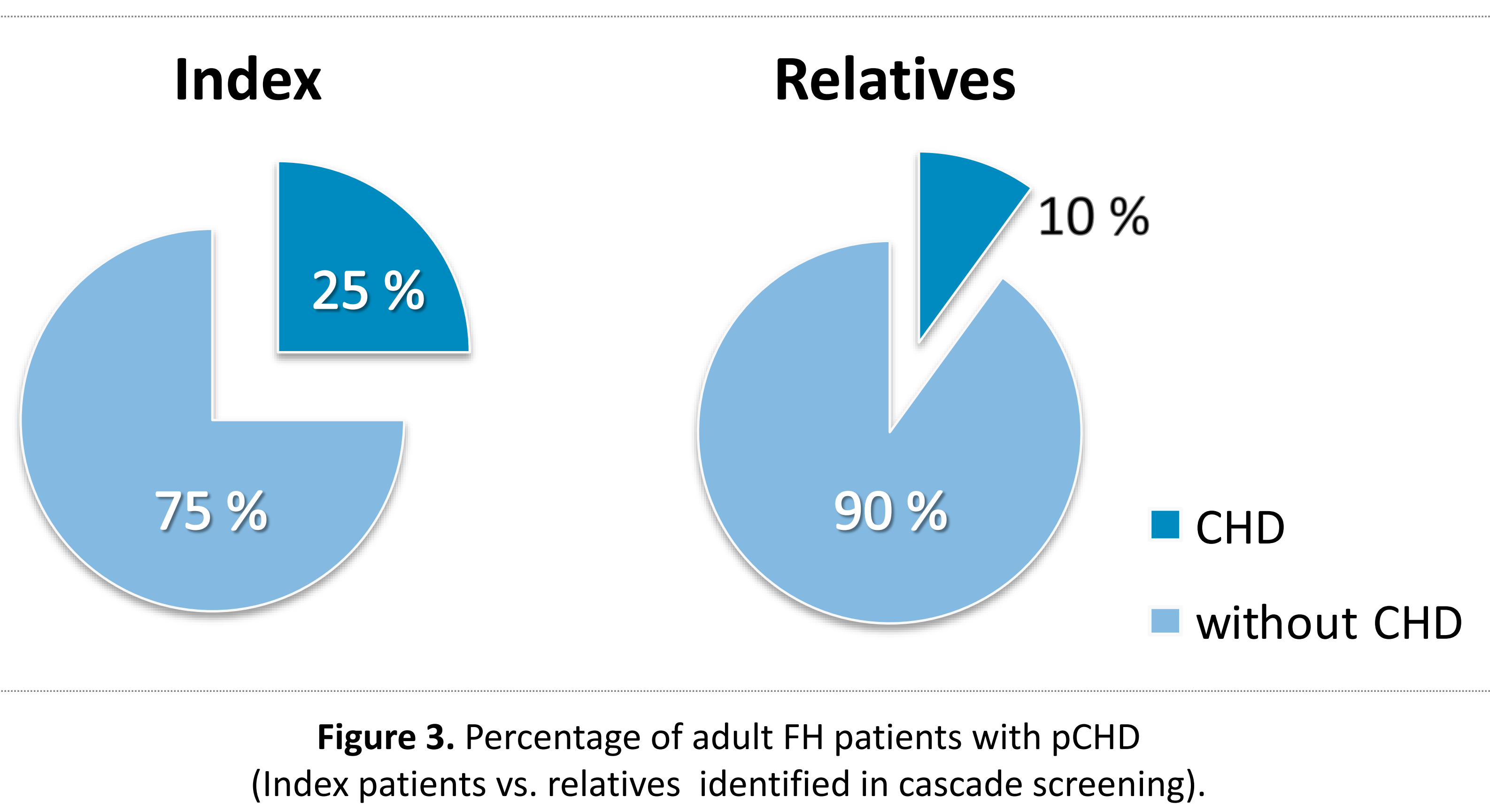

- Only $40 \%$ of relatives adults genetically identified with $\mathrm{FH}$ are in treatment vs. $79 \%$ of index adults (Figure 2).

- Only $13 \%$ of relatives adults genetically identified with $\mathrm{FH}$ have CHD vs. $25 \%$ of index adults (Figure 3).

\section{Discussion and Conclusion}

Relatives identified in cascade screening have a milder phenotype than index patients of the Portuguese FH Study. The milder phenotype is translated by lower TC and LDLc values, resulting in less relatives in treatment and with pCHD.

Some relatives (16\%) have TC and LDLc values below the criteria for FH used in the Portuguese FH study (Simon Broome Criteria) and would not be diagnosed with FH based on clinical criteria.

Genetic diagnosis of FH allows early identification of FH patients, in particular relatives with mild phenotype that would not be identified by clinical criteria alone, allowing early implementation of therapeutic measures that will reduce their increased cardiovascular risk. 